8. Humphreys, J.E.: Modular representations of classical Lie algebras and semisimple groups. J. Algebra 19, 51-79 (1971)

9. Humphreys, J.E.: Ordinary and Modular Representations of Chevalley Groups. Lecture Notes in Mathematics 528. Berlin-Heidelberg-New York: Springer 1976

10. Humphreys, J.E.: On the hyperalgebra of a semisimple algebraic group. In: Contributions to Algebra. A collection of papers dedicated to Ellis Kolchin, pp. 203-210. New YorkSan Francisco-London: 1977

11. Humphreys, J.E.: Symmetry for finite dimensional Hopf algebras. Proc. Amer. Math. Soc. 68, $143-146(1978)$

12. Humphreys, J.E., Jantzen, J.C.: Blocks and indecomposable modules for semisimple algebraic groups. J. Algebra (erscheint demnächst)

13. Jantzen, J.C.: Über das Dekompositionsverhalten gewisser modularer Darstellungen halbeinfacher Gruppen und ihrer Lie-Algebren. J. Algebra 49, 441-469 (1977)

14. Kac, V., Weisfeiler, B.: Coadjoint action of a semi-simple algebraic group and the centre of the enveloping algebra in characteristic p. Indag. Math. 38, 136-151 (1976)

15. Kostant, B.: Groups over Z. In: Algebraic Groups and Discontinuous Subgroups. Proceedings of Symposia in Pure Mathematics 9 (Boulder 1965), pp. 90-98. Providence, R.I.: Amer. Math. Soc. 1966

16. Steinberg, R.: Lectures on Chevalley Groups. New Haven: Yale University 1967

17. Sullivan, J.: Simply connected groups, the hyperalgebra, and Verma's conjecture. Preprint

Eingegangen am 6. September 1978

\title{
Nachtrag bei der Korrektur
}

Neuestens bat H.H. Andersen in seinem Preprint „The strong linkage principle" einen allgemeinen Beweis der Eigenschaft $(L)$ von 5.5 vorgelegt. Nach $5.5(6)$ ist damit auch die Verteilung der einfachen $\mathbf{u}_{n}$-Moduin auf die Blöcke von $\mathbf{u}_{n}$ bekannt. 